\title{
AN ECONOMETRIC ANALYSIS OF THE RELATIONSHIP BETWEEN AGRICULTURAL PRODUCTION AND ECONOMIC GROWTH IN ZIMBABWE
}

\author{
Alexander Mapfumo, Researcher \\ Great Zimbabwe University, Masvingo, Zimbabwe \\ E-mail: allymaps@gmail.com
}

\begin{abstract}
In Less Developed Countries (LDCs) like Zimbabwe, agricultural production has been regarded by several studies as a paramount prerequisite for industrialization and economic growth. The idea behind this view is that, as agricultural production increases, countries are able to produce more food with less labour input which allows them to feed their growing population while releasing labour for the manufacturing sector and other sectors of the economy hence the process will lead to economic growth. The main objective of this study was to investigate how agricultural production affected economic growth in Zimbabwe from 1980-2010. The Log linear growth regression model was employed where gross domestic product was the dependant variable and the explanatory variables are the major crop products and factors which affect it. Four major crops which were included in the model are tobacco, maize, coffee and cotton. Moreover, a dummy variable for the prevailing weather conditions was also included in the model. The regression analyses were performed using Econometric-views 3 (E-views 3) statistical package. Regression was carried out on time series data for the period 1980 to 2010. The data was tested for stationarity and for autocorrelation. Problems of non stationarity of data were corrected by differencing the trending series. Results from the empirical analysis provide strong evidence indicating that agricultural production is important in improving the wellbeing of countries especially in LDCs. The results from this study suggest that the value of agricultural production of tobacco, maize and cotton positively affects economic growth in Zimbabwe from 1980 to 2010.
\end{abstract}

\section{KEYWORDS}

Economic growth; Agricultural production; Zimbabwe.

In developing countries like Zimbabwe, an increase in agricultural production will mean more adequate food supplies and use of scarce foreign currency for other imports (Sherman, 1960). Moreover, when a country attains food surplus, more foreign currency will be available for development to other sectors of the economy. Eventually, non agricultural sectors of the economy would achieve sufficient momentum to provide employment for many of the underemployed workers in agricultural and non agricultural sectors leading to economic growth. Consequently, improvements in performance of the economy can be initiated by developments in agriculture.

There is a need to know the relationship of agriculture production to economic growth since development policies in Zimbabwe has been primarily based on the assumption that agriculture production is of paramount importance to the performance of the Zimbabwean economy.

Various agricultural performance indicators provide evidence of the relative deterioration of agricultural production since independence. For instance, the total agricultural production per capita and the food production per capita index have been falling, particularly since 2000 . This partly explains the rampant food shortages that Zimbabwe has witnessed, with consequent increases in domestic food prices and the dramatic increases in agricultural imports that have been observed since 2000. Yield levels usually averaging below $1 \mathrm{t} \mathrm{ha}^{-1}$ have resulted in persistent cereal deficits despite the large area put under production each year. Declining soil fertility, erratic precipitation patterns, high input costs and unstable market conditions have all affected agricultural production in Zimbabwe.

Agricultural production in Zimbabwe. According to FAO (2012), Zimbabwe has a diversified agriculture sector which accounts 11 to 20 percent of the country's annual gross 
domestic product being generated by agriculture as well as 45 percent of exports. Moreover, it also provides over 70 percent of the population directly and indirectly employment and among those who are directly linked to farming about 75 percent rely on rainfed farming systems. The agricultural sector is composed of large scale commercial farming and small scale farmers, with the latter occupying more land area but located in regions where land is relatively infertile with more unreliable rainfall. Zimbabwe is a tropical country which generally experiences a dry savannah climate. Farmland in Zimbabwe is divided into five natural regions on the basis of soil type, rainfall amounts and temperature and climatic factors (refer to Figure 1) (Mapfumo et al, 2012).

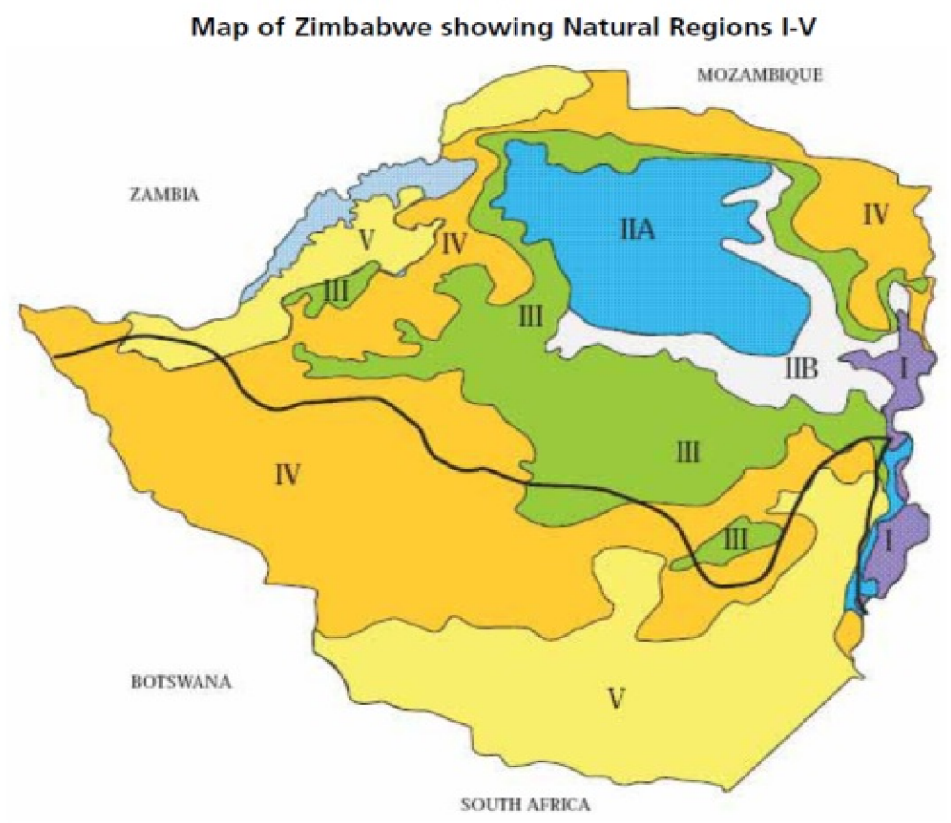

Figure1 - Agro-ecological zones in Zimbabwe (Source: FAO, 2012)

Model specification. This study used a modified log linear growth model used by Fan, Hazel and Thorat (2000). The dependant variable is Gross Domestic Product (GDP) and the independent variables include the production of Tobacco, Maize, Coffee and Cotton. According to FAO (2009), the crops outlined are the major crops grown in Zimbabwe. The outlined crops were considered as part of the analysis, basing on their contribution to agricultural production in Zimbabwe.

The log linear regression model is as follows:

$$
\log \text { GDP }=\beta_{0}+\beta_{1} \log \text { TOBC }+\beta_{2} \text { Log COFFE }+\beta_{3} \log \text { COTN }+\beta_{4} \log \text { MAIZE }+\beta_{5} \text { Dummy, }
$$

where Log GDP is the logarithm for Gross Domestic Product (GDP), $\beta_{0}$ is a constant and $\beta_{1}$, $\beta_{2}, \beta_{3}, \beta_{4}$ and $\beta_{5}$ are parameters to be estimated. Log TOBC, COFFE, COTN and Log MAIZE are the logarithms for the value of agricultural production for Tobacco, Coffee, Cotton and Maize respectively. The dummy variable represents the prevailing weather conditions.

Variables used in the model. Gross Domestic Product (GDP). In this study GDP is taken as a proxy for economic performance which measures the total amount of goods and services produced in an economy (Lipsey \& Crystal, 1999). It measures how big the economy is and has been chosen as a favourable indicator in this case because it captures all the variables that concerns economic growth. GDP has been included because it measures the output produced in any one period at prices of the same base year.

Tobacco (TOBC). Zimbabwe is the world's third largest producer of flue cured tobacco after the USA and Brazil (FAO, 2012). Tobacco has always dominated the agricultural export composition, with the largest shares of \& $8 \%$ and $67 \%$ in 1992 and 1993 respectively, were 
Zimbabwe is currently ranked the sixth largest exporter of flue cured virginia tobacco after USA, India, Brazil, Argentina and Tanzania. Tobacco is the major foreign currency earner in the country, and has an estimated population of two hundred thousand people directly employed in the production of tobacco (FAO, 2012).

Maize is the staple food in Zimbabwe and it is grown in all parts of the country (FAO, 2012). Maize is mainly grown for domestic consumption, stock feed production and cattle fattening, cornflakes and starch manufacture and export purposes. Coffee (COFFE) is a commercial crop grown in Zimbabwe and the country has produced great coffee since production started in the 1960s (FAO, 2012). Coffee is grown in some parts of Nyanga and Chipinge districts, the crop is of significance to the national output as it is consumed locally and or exported to other countries bringing in foreign currency to the country. Coffee production also provides some source of employment to people in coffee grown areas.

Cotton (COTN). Zimbabwe is one of the major exporters of cotton (COTN) and the country produces high quality cotton because it is handpicked, thus helping it establish a niche market (FAO, 2012). The introduction of an input credit scheme and deregulation of cotton marketing has resulted in a massive surge in production.

The dummy variable represents the prevailing weather conditions. such as drought where one (1) value is assigned to the years when the country experienced favourable weather conditions and a value of zero (0) is assigned to the years when the country experienced bad weather conditions for agricultural production. It is expected that bad weather conditions will negatively affect agricultural production and consequently economic performance represented by GDP.

Unit root tests. The Augmented Dickey-Fuller Test (ADF) was used to test for stationarity of the time series data. In the case that the absolute value of the ADF is less than the absolute critical value, the test accepts the null hypothesis that the variable is not stationary. If the calculated ADF test statistic is greater than critical t-values, then the null hypothesis will be rejected. The Unit Root tests were conducted on the 5 variables which are shown on Table 1 below.

At levels, the test statistics over the entire range were less than the critical values for the ADF at $90 \%$ level of confidence. This confirms that the time series variables are nonstationary as predicted by economic theory. It is therefore possible to accept the null hypothesis of non-stationarity of agricultural production and economic growth data. As is well known, the non-stationary data series are poor candidates for reliable regression Statistical Properties of Variables since they yield spurious results that are useless for predictive purposes, it was therefore necessary to correct them for non stationarity. The non-stationarity of time series data implied that the data required to be differenced in order to become stationary since the absolute calculated ADF test statistics were less than critical t-values.

Table 1 - Summary of test root results

\begin{tabular}{|c|c|c|c|}
\hline Variables & ADF test & Order of integration & Decision \\
\hline GDP & $-3.811295^{*}$ & 1 & Stationary \\
\hline Tobacco & $-6.856098^{*}$ & 2 & Stationary \\
\hline Maize & $-3.732868^{*}$ & 1 & Stationary \\
\hline Coffee & $-5.496218^{*}$ & 2 & Stationary \\
\hline Cotton & $-4.460879^{*}$ & 1 & Stationary \\
\hline
\end{tabular}

Key ${ }^{*},{ }^{* *},{ }^{* *}$ denotes $1 \%, 5 \%, 10 \%$ levels of significance respectively

After taking the first difference GDP, cotton and maize production become stationary at 99\% level of confidence. However tobacco and coffee production required second differencing to become stationary at $99 \%$ level of confidence. Government agricultural expenditure on extension variable was also stationary at $90 \%$ level of confidence.

Johansen cointegration tests. The series for all the variables in the model used were tested for cointegration using the maximum eigenvalue tests. The maximum eigenvalue tests indicate that there are 3 cointegrating variables, on Table 1. It indicates that the real GDP and the explanatory variables are cointegrated at $95 \%$ level of confidence. 
Table 2 - Johansen cointegration tests

\begin{tabular}{|c|c|c|c|}
\hline $\begin{array}{l}\text { Hypothesized } \\
\text { No. of CE(s) }\end{array}$ & Eigenvalue & Likelihood Ratio & 0.05 Critical Value \\
\hline None * & 0.805280 & 106.2067 & 68.52 \\
\hline At most 1 * & 0.601239 & 58.75713 & 47.21 \\
\hline At most $2^{*}$ & 0.553949 & 32.09475 & 29.68 \\
\hline At most 3 * & 8.682399 & 8.682399 & 15.41 \\
\hline At most 4 & 0.433233 & 0.433233 & 3.76 \\
\hline
\end{tabular}

Max-eigenvalue test indicates 3 cointegrating variables at the 0.05 level

* denotes rejection of the hypothesis at the 0.05 level

Long run relationship. Table 3 shows results of long-run estimates in which real GDP was set as the dependent variable and the rest of the variables were defined as the explanatory variables. The detailed results obtained from the regression are shown on Appendix $\mathrm{E}$. Both $\mathrm{R}^{2}$ and adjusted- $\mathrm{R}^{2}$ show quite significant outcomes at $89.5 \%$ and $87.2 \%$, respectively. The adjusted $R^{2}$ of 0.871777 implies that about $87 \%$ of the variations in GDP are explained by the explanatory variables (tobacco, coffee, cotton, maize productions and a dummy variable for prevailing weather conditions).

Table 3 - Results of long run estimates

\begin{tabular}{|c|c|c|c|c|}
\hline Variable & Coefficient & Std. Error & t-Statistic & Prob. \\
\hline C & -40.72812 & 6.500022 & -6.265844 & $0.0000^{* k *}$ \\
\hline LOGTOBC & 6.194994 & 0.682738 & 9.073751 & $0.0000^{* * *}$ \\
\hline LOGCOFFE & -0.021835 & 0.002232 & -9.782776 & $0.0000^{* * *}$ \\
\hline LOGCOTN & 0.056861 & 0.015223 & 3.733464 & $0.0011^{* * *}$ \\
\hline LOGMAIZE & 0.000861 & 0.001627 & 0.529255 & 0.6017 \\
\hline DUMMY & -0.648083 & 0.750908 & -0.863065 & 0.3970 \\
\hline R-squared & 0.894674 & \multicolumn{2}{|c|}{ Mean dependent var } & 17.03759 \\
\hline Adjusted R-squared & 0.871777 & \multicolumn{2}{|c|}{ Sum squared resid } & 53.97165 \\
\hline S.E. of regression & 1.531859 & \multicolumn{2}{|c|}{ F-statistic } & 39.07389 \\
\hline Durbin-Watson stat & 1.799344 & \multicolumn{2}{|c|}{ Prob(F-statistic) } & 0.000000 \\
\hline
\end{tabular}

* $(P<0.10)=10$ percent significance level

$* *(P<0.05)=5$ percent significance level

$* \star *(P<0.01)=1$ percent significance level

The figure 1.799344 of the Durbin Watson Statistic $(1.5<\mathrm{DW}>2.5)$ is close to the optimum level of 2 (E-Views, 1997) and shows that there is no autocorrelation between real GDP and the explanatory variables. The functional form of the equation is therefore expected to be near optimal on the basis of the results. A positive relationship between real GDP and tobacco production was obtained. The coefficient of 6.194994 means that for every one percent increase tobacco production, real GDP increases by $6,1 \%$ on average. This may have occurred since tobacco is a high value cash crop which is suitable mainly in natural regions I and II. Moreover, it shows that the variable is significant at all levels. This shows that the variable tobacco production is significant in explaining real GDP since the absolute value of $t$-value exceeds 2 . The variable is said to be statistically significant since the test statistic lies in the rejection region. Moreover, the probability is 0.000 which signifies strong significance at $1 \%$.

The results show that there is a positive relationship between GDP and the value of cotton produced, that is, a one unit increase in Cotton production will lead to an increase in real GDP in Zimbabwe by 0.06 and is significant as noted by a probability of 0.0011 and tstatistic of 3.733464 . There is also a positive relationship between GDP and Maize as denoted by a coefficient of 0.00086 however it is statistically insignificant in explaining variations in real GDP. However, there is an inverse relationship between GDP and Coffee production as denoted by a coefficient of -0.021835 . This shows that a 1 unit increase in the value of Coffee produced will lead to a decrease in GDP of 0.021835 . This might due to the fact that the new black farmers lacked the expertise for coffee production. 
Basing our decision on the rule of thumb, GDP, Tobacco, Coffee and Cotton are significant because the $t$ - statistics are greater than 2 . The dummy variable for prevailing weather conditions shows that it is negatively related to economic growth but the variable indicates that it is statistically insignificant since variable has a t-statistic absolute value of 0.863065 which is less than 2 (following the rule of thumb) hence no meaningful inferences could be drawn from the relationship.

Recommentations. In the Zimbabwean economy, agricultural crop production generally has proven to have a positive and significant impact on economic growth except for coffee production. Declines in agricultural production have thus been accompanied by declines in GDP growth, this suggests that in order for the country to achieve sustainable economic growth, which is a prerequisite for development, this growth has to be primarily from the agricultural sector and then should spread to the other sectors through various linkages.

Top priority should be given to the development of the agricultural sector in order to ensure consistent output levels. Irrigation systems should be developed to this end and other measures aimed at mitigating the effects of climate change should also be swiftly implemented.

While this does not mean that other sectors should be neglected, it does mean that agriculture should be given preferential treatment especially supporting the production of high yielding cash crops such as tobacco and cotton which have high positive impact on economic growth hence improving performance of Zimbabwe's economy.

\section{REFERENCES}

[1] E-VIEWS (1997), E-Views Users' Guide Version 3, Irvine, California, Quantitative Micro Software.

[2] Fan S, Hazell P \& Thorat S (2000). Government Spending, Agricultural Growth and Poverty Reduction in India, American Journal of African Economics. Vol.5, no. 4, pp. 133-165.

[3] FAO (Food and Agriculture Organization) (2012). Conservation Agriculture and Sustainable Crop Intensification: A Zimbabwe Case Study. Plant production and protection division. Food and Agriculture Organisation of the United Nations, Rome. Integrated Crop Management Vol.17-2012.

[4] Lipsey R \& Crystal A (1999). Principles of Economics, Oxford University.

[5] Mapfumo A, Mushunje A \& Chidoko C (2012). The impact of government agricultural expenditure on economic growth in Zimbabwe. Published by Journal of Economics and Sustainable Development (JESD), Vol.3, No.10, 2012.

[6] ZCATF (2009). Farming for the Future: A Guide to Conservation Agriculture in Zimbabwe. Zimbabwe Conservation Agriculture Task Force, Harare. 